\title{
A Call to Incorporate Child Rights and the Plight of Child Carers into the Nursing Undergraduate Curriculum and Why
}

Johanna McMullan

Queens University Belfast School of Nursing and Midwifery Belfast, Northern Ireland, United Kingdom

*Corresponding author: Johanna McMullan, Queens University Belfast School of Nursing and Midwifery Belfast, Northern Ireland, United Kingdom, Tel: 7855395598;

E-mail: j.mcmullan@qub.ac.uk

Received date: June 26, 2018; Accepted date: July 26, 2018; Published date: July 31, 2018

Copyright: $\odot 2018$ McMullan J. This is an open-access article distributed under the terms of the Creative Commons Attribution License, which permits unrestricted use, distribution, and reproduction in any medium, provided the original author and source are credited.

\section{Abstract}

The primary aim of this paper is to apply children's rights principles to the area of child carers. It will describe and examine the current laws and acts which exist to "protect" young carers, and discuss if they are effective or indeed helpful through a child's rights lens. Discussion will focus on if there is a conflict between children's rights, the research on young carers, current policy and children's well-being. Finally, the potentially helpful role and obligation of Registered Nurses in safeguarding such children from a Children's Rights perspective will be discussed.

Keywords: Child carers; Child rights; Nursing obligations; Education

\section{Introduction}

As a newly qualified staff nurse working in Accident and Emergency the plight of "child carers" shocked me. Health care professionals would gather information from children such as medical history even personal information such as bowel movements or suicidal thoughts with no apparent insight as to how inappropriate this was. I questioned this with senior colleagues and was brushed off as much as to say it's not our problem. The primary aim of this paper is to apply children's rights principles to the area of child carers. It will describe and examine the current laws and acts which exist to "protect" young carers, and discuss if they are effective or indeed helpful through a child's rights lens. Discussion will focus on if there is a conflict between children's rights, the research on young carers, current policy and children's well-being. Finally, the potentially helpful role and obligation of Registered Nurses in safeguarding such children from a Children's Rights perspective will be discussed.

\section{Childhood and Caring}

Within western constructions of childhood, children are not expected (or encouraged) to take on substantial or regular caregiving responsibilities [1]. "Childhood" is viewed as a special or protected phase, with adults, state agencies and social welfare professionals charged with safeguarding and protecting children until they make the transition into adulthood [2]. One expects therefore children to be cared for as opposed to providing care. The concept of child carers came into recognition in the late 80's with what Olsen et al. [3] describes as "an explosion of interest" in the 1990's as if their plight had suddenly come to society's consciousness. Descriptive studies by Fallon et al. [4] Bilsborrow et al. [5] Meredith et al. [6] and Aldridge et al. [7] had young carers experiences as their focus while authors such as O'Neil et al. [8] aimed at identifying numbers and identification of the tasks they performed and how frequently.

It is widely accepted that many children do indeed take on various chores but the exact number is still unknown, and defining their role is riddled with difficulties [9]. Child or young carer are the two most widely used terminologies, however their age group varies in literature from under 16, 18 and 25, and some literature refers to children as being carers if they carry out any caring task while others only classify them as "carers" if they have no choice, as of this decade there is still no consensus on the definition of a young carer [9]. There are various reasons as to why a child cares with the main reason being no appropriate adult to do so otherwise hence why a huge proportion of those are in lone parent families [10] or that the adult has not received the support to which they are entitled and if professionals fail to address the needs of children in this context [11]. It must be remembered that many children chose or want to take on caring responsibilities, which is quite different to having to and the distinction between the two is imperative to understanding their needs. Many children with a parent with a terminal illness want to provide some care, or helping a frail elderly relative, or younger sibling and certainly some degree of caring in childhood is both routine and to be valued and encouraged as a part of "healthy" child development [12]. The extent of the role and what duties this entails are also important. Literature details that the time spent caring per week can range from less than $5 \mathrm{hrs}(15 \%)$ with an average of $15 \mathrm{hrs}$ per week (50\%) with a staggering $18 \%$ of children spending between $30-50$ hours carrying out caring responsibilities [13]. The types of chores range from gardening to toileting, and are classified as domestic, general (shopping errands), intimate, emotional and child care, with the most common tasks being domestic and emotional caring. There are also variations between the genders with girls being more likely (but not exclusively) to carry out intimate care and child care [14] with boys engaging in more general tasks and children become more heavily involved in caring as they get older [15] and a disproportionate number of carers from ethnic minorities possibly linked to poverty [16].

For the first time the decennial UK census (2001) asked about caring responsibilities and general self-rated health. Of all children aged between 5 and 15,1.4\% provided care of which a third provided care more than 20 hrs a week with a substantial number more than 50 hrs a week. Doran et al. [17] analyzed the results and also discovered a direct correlation between the number of hours' children spent caring and rating their health as "not good", and commented that if they were 
paid employees these carers would be in contravention of the European Working Time Directive. This was not the first time concern has been raised in fact Siddall et al. [18] describes how the overwhelming view within debates about young carers was that it causes serious problems for the child. The Tameside study [19] attempted to ascertain the extent to which caring impacted on children's lives and makes for depressing reading with friendship difficulties, limited time for social and leisure activities, limited time for school and homework all highlighted. However, these studies were all descriptive rather than interpretative asking folk such as school pastoral staff rather than the children themselves. Aldridge and Becker's et al. [7] was the first to investigate in-depth using qualitative methods child carers lived experiences. It revealed that young careers are often forced into undertaking intimate caring responsibilities that are both distressing and unappealing to them as well as to the care receiver, and how physical tasks such as lifting put young carers at risk. The subjects of this project were recruited from child carers groups and interviews were carried out in the presence of the parent or appropriate adult, so although progressive compared to previous research attempts in this area still arguably limited with perhaps the children being cautious about what they say in front of the person receiving the care and indeed hardly a true picture of the world of child carers with the sample made up entirely of those already being supported [20,21]. Recently other authors have acknowledged that what is missing is "deeper insight" about children's experiences which is what should drive policy [22], noting that research which purports to be about families often centers on parents and overlooks the experiences and view of children [23]. Other research which was quantitative in nature identified many negative associations with being a child carer such as lower academic attainment, health problems etc., many of which were published in journals such as Child Abuse Review [24-26].

Despite a lack of a precise definition, the bulldozer of research resulted in children who care going from a baseline of zero in the late 80 's early 90 's to a major child welfare concern in the next decade [27], with calls for social services to be mobilized to protect these child carers and claims that the role of child carers denies children of their rights. Policy making swung into action based on the plethora of research published describing the negative impact of care-giving on young carers (seemingly ignoring the few detailing some positive impacts nor taking into consideration the young person's views) which led to polices and laws to protect young carers being rolled out to cover all, but which it could be argued are not tailored and therefore fit none [28].

\section{Child Rights}

As far back as 1920's pioneers such as Banks P [13] recognized that children were of as much importance as adults yet vulnerable. The Declaration of Geneva in 1924 made a series of statements which could be argued was the emergence of Child Rights although this as a concept struggled to find a definition. The United Nation (UN) was established in 1945 and aimed to preserve peace through international collaboration, collective security and promote the respect for human rights. The Universal Declaration on Human Rights (UDHR) was signed in 1948, which is a declaration i.e. it is not legally binding but seen as a statement of intent or principle, "a common standard of achievement". Since then it has implemented a range of significant human rights treaties which are legally binding which replicate the rights in the UDHR, one of which is The Convention on the Rights of the Child with 54 articles poised and was adopted and opened for signature, ratification and accession by General Assembly with entry into force on 2nd September 1990. The UN Treaties are enforced through the system of periodic reporting to the UN Treaty Monitoring Bodies, and UN's Special Rapporteurs' offers an additional mechanism which is widely regarded as an important weapon in the arsenal of human rights monitoring, but in fact is limited as they are devoid of special powers of investigation or enforcement. The Council of Europe formed in 1949 currently has 46 members and exists to define human rights and democracy by producing a series of instruments that relate to children and are of importance as applied to UK Law. Key terms include "Hard Law" and "Soft Law". Hard Law is when a States ratification becomes legally binding and soft law relates to rules/ declarations rather than law. The Child Rights stipulated by the UN are often quoted in literature relating to child carers.

\section{Child rights and Child Carers}

The literature on child carers especially those written in the early days argue that many child rights are breached when children are carers. Article 19 states "all appropriate legislative, administrative, social and educational measures to protect the child from all forms of physical or mental violence, injury or abuse, neglect or negligent treatment, maltreatment or exploitation, including sexual abuse". This article is quoted alongside Article 32 which recognizes the right of the child to be "protected from economic exploitation and from performing any work that is likely to be hazardous or to interfere with the child's education, or to be harmful to the child's health or physical, mental, spiritual, moral or social development'. With evidence of some child carers "working" up to 50 hrs per week [17] it can be argued that this is a breach of article 32 part 2 (a) "provide for appropriate regulation of the hours and conditions of employment" and with children as young as 5 being identified as carrying out caring roles part 2 (a) "provide for a minimum age or minimum age for admission to employment" it is easy to argue that many young carers are in fact being economically exploited. Furthermore, many of the tasks which children are engaged in include lifting an adult and/or performing intimate care [29] is potentially damaging both physically and psychologically. "Lifting", of adults is banned from all care contexts be it hospital or community settings by the Nursing and Midwifery Council [30], those requiring moving and handling have a full nursing assessment of needs and only those trained in techniques with the correct equipment are permitted to do so. Institutions which fail to provide such equipment or training for personnel can face prosecution. It seems inconceivable then that state parties who have knowledge of children lifting without such training or equipment can let this happen without breaching these rights and Article 36 "protect the child against all other forms of exploitation prejudicial to any aspects of the child's welfare".

Article 31 recognizes the right of the child to rest and leisure, "to engage in play and recreational activities appropriate to the age of the child'. Literature details that caring can be linked to adverse social outcomes as it can limit young people's opportunities for socialising and private pursuits such as play [14], or extracurricular activities [8]. Collins et al. [31] and Obadina et al. [32] report young carers feeling isolated and different from their peers, feelings of resentment, anger, emotional exhaustion and stress are also common and O'Dell et al. [33] found child carers to be socially isolated from their peers due to their responsibilities. Therefore, article 31 in some circumstances could be breached as could article 27 "standard of living adequate for the child's physical, mental, spiritual, moral and social development". Of 
most concern in literature is the negative impact of caring regarding education and health. It is of little doubt that education is affected with poor attendance [34] higher dropout rates [35] lower attainment in examinations [36] and higher levels of stress and poorer mental health compared to other children [37] due to their responsibilities. Article 28 includes part (e) "take measures to encourage regular attendance at schools and the reduction of drop-out rates". Less than $22 \%$ of carers reported any kind of help or allowances or even assessment of their needs to enable them to complete school or college work, with many reporting punitive measures being put in place despite them explaining the reason for incomplete work [38] thus compiling stress and making them believe dropping out was the only answer. Therefore, it could also be argued that in many incidences article 29 "the education of the child shall be directed to (a) the development of the child's personality, talents and mental and physical abilities to their fullest potential' is also breached if child carers are not able to engage fully with all aspects of school life as is article 24 "enjoyment of health" with so many suffering from stress and anxiety [39].

This body of literature resulted in the general opinion that being a child carer has negative impacts and thus legislation was brought in to "protect" said child carers. To quote breaches of some child rights is in my opinion cherry picking aspects of the convention without looking at child rights as a whole and taking into consideration broader and fundamental child rights nor does it take into consideration potential benefits of caring.

\section{Legislation and Young Carers}

The first legislation to immerge was The Children's Act [40] which stipulated that some child carers be assessed if they met certain criteria but was criticised as large numbers of carers were therefore overlooked and was followed by the Carers Strategy $[41,42]$ which is very clear in its vision but sadly even in 2017 has failed to make an impact on policy. The Community Care Act [43] which translated into Northern Ireland in 1993 disappointingly failed to acknowledge any carers under the age of 18. The result was an outpouring of anger in literature regarding the inadequacies of these policies which lead to the Carers Act 1995 [44] which insisted carers' needs were important but secondary to the needs of the care receiver [45] and carers could only be assessed if the recipient was reassessed. Furthermore, in Northern Ireland this act translated into the Children's Order (1995) which made assessment of child carers statutory requirement and in fact describes all young carers as vulnerable and classifies them as children in need [46], this was a rather knee jerk reaction bordering on ridiculous.

Young carers are not at inevitable risk of harm or developmental delay. As a young teenager I was mobilised to prevent an Aunt with disabilities from going into long term care by carrying out household chores and staying overnight with her. Indeed, Becker et al. [1] writes that some level of attachment and caring by children is viewed as necessary for "healthy" psycho-social development in most societies and there are some benefits.

Reinforced bonds between children and parents were found by Gopfert et al. [47], a sense of identity and purpose with many feeling proud of their role [48] developing skills needed in adulthood, enhanced coping mechanisms and contributing to the integrity and resilience of families [13].This is a small body of research primarily because there appears to be a distinct lack of good qualitative literature involving children asking them about what it's like to care or their feelings about it. Much of the literature as discussed above is quantitative focusing only on the negatives rather than potential positive aspects [49]. The negatives cannot be ignored however children's development and childhood experiences are not inevitably adversely affected when caring, only when it becomes long term and disproportionate i.e. when the practical and emotional responsibilities is not congruent with the child's age [50] or changing needs of the child e.g. increasing want or need to study socialize etc. [51]. There is much evidence to suggest that this all-inclusive policy of prejudging all child carers as 'at risk' did considerable harm. Unfortunately, it created fear amongst families' that the child would and in many cases were removed from the family for "their best interests" and even the perceived threat of intervention caused anxiety. It is now of major concern to policy debates those young carers and their families actively hide their situation from outside agencies for example in many instances schools are unaware of the caring duties performed by their pupils [52]. Smyth et al. [53] found that young carers have gone "underground" and stay hidden and beyond the reach of services and supports. O’Dell et al. [33] state that many child carers underestimate their responsibilities and actively hide from social services. A further criticism of this policy is that to imply the child's rights have been breached is to imply that it was the parent who is the culprit. Newman et al. [27] argues that the pre occupation with rights of the child has diverted attention and possibility resources away from the needs of the whole family. This could result in parents feeling disempowered and pathologies by having their illness effecting their child Critics of child rights include those who say they interfere with other rights this might be the case here with parents right to stay in a family situation and fail to take into account the rights of the cared for person. Perhaps a more useful definition or approach to the situation is not how the child cares, their age, what tasks, who they care for etc. rather the impact these duties have on them and a broader examination of all their rights including the general principles rather than quoting a few to justify policy.

\section{The general principles}

Articles 2, 3, 6 and 12 are known as the general principles. Article 2 refers to non-discrimination stating "without discrimination of any kind irrespective of the child's or his or her parent's or legal guardian's race, colour, sex, language, religion, political or other opinion, national, ethic or social origin, property, disability, birth or other status". Newman et al. [27] discusses how policy dictates that every family where there is a greater likelihood of children becoming carers including where there is sickness or disability is highly discriminative towards disabled parents implying that being a disabled parent is somehow "hazardous" to children. Smyth et al. [53] describes how policy identified many children as child carers because they carried out some chores or simply because they had a disabled parent without any evidence of negative impact to the child and Seddon et al. [54] Cass et al. [55] describes how there is no consideration made as to how much children would do in a normal family situation before tasks carried out by children of disabled parents were labelled carers. Would this have meant I would have been considered a child carer rather than loving relatives by policy if the Aunt I cared for was my parent? Furthermore, article 16 states "no child shall be subjected to arbitrary or unlawful interference with his or her privacy, family, home or correspondence, nor to unlawful attacks on his or her honour and reputation". By referring a child to social services purely on the grounds that a parent is ill or disabled and therefore they might be exposed to negative consequences without evidence of such would breach this right. 
Article 3 states "the best interest of the child shall be a primary consideration". It is interesting that this article states the child's best interest is " $a$ " primary consideration not 'the' primary consideration, and in some cases it was argued that it was in the child's best interest to be removed from the family situation or to be stopped from caring. However, what about the child's well-being generally? For a child to be in a state of well-being they need to be loved or feel that they are loved or at least cared for by others [56]. There is no right to love in the UN convention on the Rights of the Child and therefore it could be argued that the need to be loved and cared for is of no consideration when considering what is in the child's best interest even though to stay with loving parents/parent would be best? It is of little doubt that it is in children's best interests to stay in the family situation [57] rather than in care, but if the issue of rights is to be debated when legislators are considering best interest as " $a$ " consideration they should also take into account articles 7 and 8 which quite clearly state "the right to know and be cared for by his or her parents" and "respect the right of the child to preserve his or her identity, including nationality, name and family relations". It would appear that there is a lack of understanding of what effective parenting are [58] as illness or disability does not undermine parenting skills only some abilities.

The third general principle article 6 states "the inherent right to life: state parties shall "ensure to the maximum extent possible the survival and development of the child". To ensure development child carers should be supported in carrying out these tasks but to remove them from the family would undermine their development.

The last general principle article 12 refers to participation, "the child who is capable of forming his or her own views the right to express those views freely in all matters affecting the child, the views of the child being given due weight in accordance with the age and maturity of the child'. This right is fundamentally breached with regards to the issue of child carers. As discussed there is a lack of good qualitative research where children fully participate and give their views on caring. Most is quantitative, and those that are qualitative were either conducted with adults present or a lack of anonymity assured calling into question the results reliability or questions posed to children asked them to discuss the negative impacts of caring only. It could perhaps be argued that as well as denying their right to participation this type of research also breaches article 13 the right to freedom of expression. It was on this body of literature that current policy was formed and therefore is highly questionable. Lundy et al. [59] reminds us that children must have safe and inclusive opportunity to form and express a view and be facilitated to express views freely in a medium of choice which frankly is lacking in the literature on child carers. Furthermore, the broad sweeping referral of any child who "care" for assessment conducted by social workers with little or no insight into the physical and emotional demands of caring without consultation of the child with regards to how or if it affects them both negatively and positively denies them this fundamental right. Where it is without doubt that the child is subjected to negative consequences this right of participation must still be taken into consideration at the time of intervention, with the child's voice being heard with regards to what would be helpful to them as opposed to third parties mobilizing resources or removing the child. As discussed there is a fear amongst young carers of intervention and state parties must also remember article 9 part 1 "a child shall not be separated from his or her parents against their will except when competent authorities subject to judicial review determine", and part 2 of article 12 "the child shall in particular be provided the opportunity to be heard in any judicial and administrative proceedings affecting the child'. Again Lundy's model of participation [59] reminds us that article 12 also states the right to views given due weight, meaning the audience must listen to those views and those views must be acted upon as appropriate. Do the newer Acts finally take this into consideration?

In 2014 in England and Wales the Children's and families Act and Care Act of 2014 [58] became legislation and declares young carers as "rights holders' which has been welcomed by the Carers Trust 2015 [41] as it will strengthen the needs of both the cared for person and the care giver". The Human Rights of Carers in Northern Ireland Report [41] describe new rights to assessment for those under 18 irrespective of time or task (perhaps what is meant is a new acknowledgement of rights as they aren't new) and The Young Carers Regulations [41] does recognize the rights of the child as a young carer which is hopeful especially as it also acknowledges the importance of meeting the cared for persons need which would lessen the burden on the carer. How successful these implementations will be however is if state parties ensure the Whole Family Approach is promoted instead tensions arising between the child's rights, those of the cared for person and policy being implemented without consultation of both [60]. It is too early to tell if these new measures will be effective nor if the trust in the state by child carers and their families can be re-established. Perhaps who would or could carry out such assessments and referrals and their appropriateness to do so is of importance.

\section{The Nursing Profession and Young Carers, the way forward?}

Considerable damage was done by these sweeping policies as there was/is a general fear and reluctance to engage with social services and with research projects. This resulted in many young carers who need help being overlooked, while some who were well able and willing to carry out some caring tasks are deemed at risk [61].

Nursing is now firmly established as a profession and is bound by its own professional code of conduct and regulatory body who state that nurses "must act as an advocate for those in your care, helping them to access relevant health and social care, information and support". Lay people's perceptions of nurses are as trust worthy individual's bound by confidentiality and have unique access to not only the recipient of care but also carers. They also have good insight into the requirements of caring e.g. lifting, dispensing medication, washing and emotional care and support. It seems rather obvious then that as adults become in need of care that nurses have a responsibility to ensure adequate provisions are in place at that point to ensure children do not have to pick up and slack, or if the situation deteriorates that again nurses can and should intervene. Secondly, if some tasks are being carried out by children who want and wish to help out the nursing body would have good insight into the appropriateness of the burden and mobilise the resources as required. For example, some child carers provide only emotional support [9] which seems innocuous however this can be incredibly emotionally exhausting and psychologically damaging to any care givers [62] including trained nurses, let alone to a child. Community psychiatric nurses would be in a unique position to assess when child carers are shouldering too heavy a burden. Some tasks such as mobilising could be made safe or at least less hazardous if the carer was appropriately trained rather than making a knee jerk referral to social services. Indeed nurses pride themselves on devising and revising care plans as needs change which could be done in conjunction with the changing needs of the carer e.g. if they have exams coming up rather than what seems to be the situation at present that a battle between the child's and the care receivers needs or rights. 
Furthermore, as advocates nurses are obliged to be the voice of their patients and their families and hence should intervene if they believe their rights are being breached, whether that is because there is no intervention or indeed too much [63]. At present awareness of vulnerable adults and children are embedded into undergraduate nursing curriculums but there is no such discussion of child carers nor child rights. The MidStaffordshire enquiry [64] resulted in compulsory inclusion of carers into health care planning and education but yet again there seems to be an omission of young carers in both.

\section{Conclusion}

Any guidelines for the provision of young carers' needs or service delivery must surely be based on philosophical and pragmatic principles including the recognition and observation of children's rights, practical policy recommendations based upon these rights and "pragmatic considerations" in relation to professional intervention and service arrangements [65]. To ensure this happens to all state parties must have an understanding and be diligent in ensuring all child rights are enforced. In changing modern times with more single parent families than ever before, "sicker" individuals staying at home rather than being hospitalised than any time and in times of austerity there is potential for more children to be engaged in caring than ever before. It is my firm belief that the nurse's role must not only be to care for and be advocates for their patients but their families, and therefore there is a clear need for the awareness of child carers to be discussed at all levels in nursing and most definitely at undergraduate level. However, to ensure the mistakes of the past are not repeated rather than them being discussed just as potentially vulnerable children in need of protection, that this teaching should be done through a child rights lens to ensure nurses of the future as state parties are able to promote a whole family approach to ensuring the best possible tailored provisions are put in place in each situation to best meet the needs of those in their care.

\section{References}

1. Becker S (2007) Global perspectives on children's unpaid caregiving in the family research and policy on 'young carers' in the UK, Australia, the USA and Sub-Saharan Africa. Global social policy 71: 23-50.

2. Frank J, Tatum C, Tucker, S (1999) On small shoulders: Llearning from the experiences of former young carers. Children's Society, London.

3. Olsen R (2000) Families under the microscope: Parallels between the young carers debate of the 1990's and the transformation of childhood in the late nineteenth century. Child Society 14: 384-394.

4. Fallon K (1990) An involuntary workforce. Community Care 4: 12-13.

5. Bilsborrow S (1992) You grow up fast as well...Young carers in the UK: Research, policy and Practice. Res Policy Planning 18: 13-22.

6. Meredith H (1992) Are young carers' children in need? A report on local authorities.

7. Aldridge J, Becker S (1994) My child, my carer: The parent's perspective. Loughborough, Leics: Loughborough University.

8. O' Neil A, Platt C (1992) Towards a strategy for carers: Young carers.

9. Earley L, Cushway D, Cassidy T (2007) Children's perception and experiences of care giving: A focused group study. Couns Psychol Quarterly 20: 69-80.

10. Rose HD, Cohen K (2010) The experiences of young carers: A metasynthesis of qualitative findings. JYS 13: 473-487.

11. Dearden C, Becker S (2004) Young carers in the UK: The 2004 Report. London: Carers UK.

12. Aldridge $J$ (2006) The experiences of children living with and caring for parents with mental illness. Child Abuse Rev 15: 79-88.
13. Banks P, Cogan N, Riddell S, Deeley S, Hill M et al. (2002) Does the covert nature of caring prohibit the development of effective services for young carers? Br J Guid Counc 30: 229-246.

14. Bibby A, Becker S (2000) Young carers in their own words. London: Calouste Gulbenkian Foundation.

15. Robotham D, Beecham E, Jackson C, Penketh, K (2010) The challenges facing young carers of parents with a severe mental illness. London: Mental Health Foundation.

16. Jones A, Jeyasingham D, Rajasooriya S (2002) Invisible families: The strengths and needs of black families in which young people have caring responsibilities. New York: Joseph Rowntree Foundation.

17. Doran T, Drever F, Whithead M, Duncan WH (2003) Health of young and elderly informal carers: Analysis of UK census data. BMJ 327: 1388.

18. Sidall R (1994) 'Lost Childhood', Community Care.

19. O'Neill A (1988) Young carers: The Tameside research. Manchester: Tameside Metropolitan Borough Council.

20. Aldridge J, Becker S (2003) Children Caring for Parents with Mental illness: Perspectives of young carers, parents and professionals. Policy Press: Bristol.

21. Kellett M, Ding S (2004) Middle childhood.

22. Darbyshire P, MacDougall C, Schiller W (2005) Multiple methods in qualitative research with children: More insight or just more? Qualitative Res 54: 417-436.

23. Fargas MM, McSherry D, Larkin E, Robinson C (2010) Research with children: methodological issues and innovative techniques. Early Child Res 8: 175-192.

24. Meredith H (1991) Young carers: The unacceptable face of community care. Social work social sci Rev 3: 47-51.

25. O'Hagan K (1993) Emotional and psychological abuse of children. Open University Press. Milton Keynes.

26. Cleaver H, Unell I, Aldgate J (1999) Children's needs-Parenting capacity: The Impact of parental mental illness. The stationary office, London.

27. Newman $\mathrm{T}$ (2002) Young carers and disabled parents: Time for a change in direction? Disability Society 17: 613-625.

28. Smyth C, Blaxland M, Cass B (2011) So that's how I found out I was a young carer and that I actually had been a carer most of my life. Identifying and supporting hidden young carers. J Youth Stud14: 145-160.

29. Cree VE (2003) Worries and problems of young carers: Issues for mental health. Child Fam Soc Work 8: 301-309.

30. Nursing Midwifery Council (2008) The code: Standards of conduct, performance and ethics for nurses and midwives. London: NMC.

31. Collins J, Bayless S (2013) How caring for a parent affects the psychosocial development of the young. Nurs Child Young People 25: 16-21.

32. Obadina S (2014) Parental mental illness: Effects on young carers. BR J Nurs135-139.

33. O'Dell L, Crafter S, de Abreu G, Cline T (2010) Constructing normal childhoods: Young people talk about young carers. Disability society 25: 643-655.

34. Cluver L, Operario D, Kganakga M (2011) I can't go to school and leave her in so much pain: Educational shortfalls among adolescent 'young carers' in the South African AIDS Epidemic. J Adolesc Res 27: 1-25.

35. Sempik J, Becker S (2014) Young adult carers at college and university. Carers Trust.

36. The Children's Society (2013) Hidden from view: The experience of young carers in England. The Children's Society.

37. NIACE (2014) The really useful book of learning and earning for young adult carers. NIACE.

38. McAndrew S, Warne T, Fallon D, More P (2012) Young, gifted, and caring: A project narrative of young carers, their mental health, and getting them involved in education, research and practice. Int J Ment Health Nurs 21: 12-19.

39. Bostock A (2015) Ensuring that young carers have the support they need in school. Br J Nurs 7: 406-407. 
Citation: McMullan J (2018) A Call to Incorporate Child Rights and the Plight of Child Carers into the Nursing Undergraduate Curriculum and Why. J Nurs Care 7: 462. doi:10.4172/2167-1168.1000462

Page 6 of 6

40. Children's and Families Act (2014) London: The Stationary Office.

41. Carers Trust (2015) New rights for young carers, young adult carers and their families: an overview. Carers Trust briefing for Network Partners. London: Carers Trust.

42. Becker S, Dearden C, Aldridge J (2001) Children's labour of love? Young carers and care work. Hidden Hands: International Perspective on Childrens' Work and Labour, Falmer press, Brighton, pp. 70-87.

43. Department of Health (1990) NHS and Community Care Act. London: HMSO

44. Department of Health (1995) Carers (Recognition and Services) Act 1995. London: HMSO.

45. Hirst, $M(2002)$ Transitions to informal care in Great Britain during the 1990s. J Epidemiol Community Health 56: 579-587.

46. Lloyd L (2000) Caring about carers: Only half the picture?. Crit Social Policy 20: 136-150.

47. Gopfert M, Webster J, Nelki J (2004) The construction of parenting and its context. Parental psychiatric disorder: Distressed parents and their families.

48. Moore T (2005) Young carers and education: Identifying the barriers to satisfactory education for young carers. Youth Studies Australia 24: 50.

49. Gray, B, Robinson C (2009) Hidden children: Perspectives of professionals on young carers of people with mental health problems. Child Care Prac 15: 95-108.

50. Keith L, Morris J (1995) Easy targets: A disability rights perspective on the 'children as carers' debate. Critical Social Policy 15: 36-57.

51. Aldridge J, Wates M (2005) Young carers and their disabled parents: Moving the debate on. Disabled parents and their children: Building a better future. Ilford: Barnardos 80-99.

52. Underdown A (2002) I'm growing up too fast: Messages from young carers. Child Society 16: 57-60.
53. Smyth C, Cass B, Hill T (2011) Children and young people as active agents in care-giving: Agency and constraint. Child Youth Serv Rev 33: 509-514.

54. Seddon D, Robinson C, Reeves C, Tommis Y, Woods B et al. (2006) In their own right: Translating the policy of carer assessment into practice. BASW 37: 1335-1352.

55. Cass B, Smith C, Hill T, Blaxland M (2009) Young carers in Australia: Understanding the advantages and disadvantages of their care giving.

56. Layard R, Dunn J (2009) A Good Childhood: Searching for values in a competitive age. The Children's Society, London.

57. Dearden C, Becker S (1997) Children in care, children who care: Parental illness and disability and the child care system. Young Carers Res Group.

58. Gough D, Stanley N (2004) Parenting capacity. Child Abuse Rev 13: 1-4.

59. Lundy L, McEvoy L (2012) Children's rights and research processes: Assisting children to (in) formed views. Childhood 19: 129-144.

60. Department of Health and Social Services and Public Safety, N. Ireland (2015) Carers statistics for Northern Ireland's DHSSPS.

61. Dearsden C, Becker, S (2000) Growing up caring: vulnerability and transition to adulthood-young carers experiences. Leicester: Youth Work Press.

62. Pinquart M, Sörensen S (2003) Differences between caregivers and noncaregivers in psychological health and physical health: A meta-analysis. Psychol Aging 18: 250.

63. Boylan J, Dalrymple J (2009) Understanding advocacy for children and young people. McGraw-Hill Education (UK).

64. Francis R (2013) Report of the mid staffordshire NHS foundation trust public inquiry: Executive summary 947 . The Stationery Office.

65. Aldridge J, Becker S (1993) Children who care: Inside the world of young carers. Loughborough University. 